\title{
Violência no Município do Rio de Janeiro: áreas de risco e tendências da mortalidade entre adolescentes de 10 a 19 anos
}

\author{
Edinilsa Ramos de Souza, ${ }^{1}$ Simone Gonçalves de Assis, ${ }^{1}$ \\ Cosme Marcelo Furtado Passos da Silva²
}

RESUMO O presente estudo apresenta dados de mortalidade geral e mortalidade por causas externas (acidentes de trânsito e homicídios) entre adolescentes de 10 a 19 anos no Município do Rio de Janeiro, Brasil, no período de 1980 a 1994. O objetivo do estudo foi descrever e contextualizar a mortalidade por causas externas e identificar áreas do Município com maior risco para esses agravos. O estudo pretendeu ainda observar tendências e sazonalidades desta mortalidade e situar a violência no campo da saúde pública sob o enfoque da vigilância epidemiológica. As informações sobre a mortalidade foram extraídas das declarações de óbito cedidas pela Secretaria Estadual de Saúde do Rio de Janeiro.

Um total 20224 declarações de óbito foram investigadas. As populações usadas nos denominadores das taxas foram estimadas a partir dos censos demográficos de 1980 e 1991. Para fins de análise, o Município foi dividido em oito áreas programáticas, cada uma composta por diversos bairros circunvizinhos. Realizou-se uma análise de séries temporais para os acidentes de trânsito e os homicídios. Os resultados mostraram que as causas externas são as principais causas de morte na faixa de 10 a 19 anos e no período estudado mostraram-se crescentes, principalmente entre o sexo masculino. Os resultados demonstraram ainda a heterogeneidade da distribuição da mortalidade em diferenciados espaços sócio-econômicos do Município. O estudo aponta para a necessidade de uma integração do setor de saúde a outros setores e instituições e de uma reestruturação do sistema de saúde em função da vigilância epidemiológica à violência.

Nos anos 80, os grandes centros urbanos presenciaram o crescimento da violência, expresso no incremento da mortalidade por causas externas (1-4). A mortalidade por causas exter-

\footnotetext{
1 Departamento de Epidemiologia e Métodos Quantitativos em Saúde e Centro Latino Americano de Estudos sobre a Violência e Saúde Jorge Careli (CLAVES) da Escola Nacional de Saúde Pública / Fundação Oswaldo Cruz (FIOCRUZ).

2 Centro Latino Americano de Estudos sobre a Violência e Saúde Jorge Careli (CLAVES). Avenida Brasil 4036, sala 702, Manguinhos, RJ, CEP 21040361, Brasil. Telefone e fax: +55-21-290-4893. Correspondência e pedidos de separatas devem ser enviados para este endereço.
}

nas engloba óbitos por acidentes, suicídios e homicídios e é definida no capítulo suplementar da Classificação Internacional de Doenças (CID) (5), em sua nona revisão, sob os códigos E800 a E999.

No Brasil, as mortes por causas externas ocupavam o quarto lugar nos índices de mortalidade geral do país no início da década de 80. Já no final da década, as causas externas apareciam como a segunda causa de morte mais freqüente $(1,4)$.

O Rio de Janeiro é a capital do país que apresenta as mais elevadas taxas de mortalidade por causas externas, responsáveis pela maioria das mortes na ampla faixa dos 5 aos 49 anos de vida. Além disso, as causas externas são as principais responsáveis por anos potenciais de vida perdidos (6). Estudos recentes (6-8) mostram o crescimento das mortes por violência entre grupos cada vez mais jovens, particularmente entre crianças e adolescentes.

A utilização de métodos e técnicas epidemiológicas contribui para o estudo e o aprofundamento destas questões através da análise da distribuição da violência e da identificação de grupos e áreas com maior exposi- 
ção ao risco (9-11). Entretanto, os estudos efetuados até agora são pouco detalhados e meramente descritivos. Neste sentido, abordagens alternativas para o tema da violência estão sendo propostas no campo da saúde pública com a incorporação de novos conceitos e técnicas da vigilância epidemiológica (9-11). Este arcabouço teóricometodológico permite pensar a ocorrência dos agravos violentos tanto em termos de assistência aos casos endemicamente esperados quanto em termos de prevenção sob parâmetros explicativos mais amplos que englobam, além da ocorrência do fato isolado e do risco enquanto comportamento individual, fatores de risco do próprio ambiente. Este enfoque permite ainda pensar no controle e prevenção da violência a partir de grupos e áreas sociais mais restritos e específicos. Além disso, sob um enfoque que privilegia a vigilância à violência, as políticas e ações de saúde passam a ser regidas segundo uma ótica mais ética, calcada em prevenir o que pode ser evitado e não apenas em intervir no que pode ser tolerado. Desta forma, as políticas e ações de saúde adotariam uma visão interdisciplinar, inter-institucional e inter-setorial.

O presente estudo apresenta dados de mortalidade entre adolescentes de 10 a 19 anos no Município do Rio de Janeiro, no período de 1980 a 1994. O objetivo do estudo é, além de descrever a mortalidade por causas externas, identificar áreas do Município com maior risco para esses agravos e observar tendências e sazonalidades desta mortalidade.

\section{MATERIAIS E MÉTODOS}

Realizou-se um estudo descritivo da mortalidade entre adolescentes de 10 a 19 anos no Município do Rio de Janeiro, no período de 1980 a 1994 . As informações sobre a mortalidade, extraídas das declarações de óbito e transcritas para microcomputador, foram cedidas pela Secretaria Estadual de Saúde do Rio de Janeiro. Para o Estado do Rio de Janeiro o registro da mortalidade é de cerca de 100\% (12), o que garante uma boa representatividade da mortalidade.

Os óbitos classificados segundo o local de ocorrência do evento que levou à morte na faixa etária investigada receberam a codificação de três dígitos da CID-9 (5) que compreende os códigos E800-E999. Estes códigos correspondem ao grupo V01 a Y98 da décima revisão da CID (13) que entrou em vigor a partir de janeiro de 1996. Foram analisadas as seguintes variáveis registradas na declaração de óbito: sexo, idade, local de ocorrência da morte, residência, grau de instrução, local de nascimento e ocupação ou profissão da vítima, além de instituição que atestou o óbito. A mortalidade geral e principais causas de morte foram investigadas.

Os dados foram analisados em termos da área geográfica em que o óbito ocorreu. Adotou-se no estudo a divisão administrativa utilizada pelo setor de saúde para o Município do Rio de Janeiro. Assim, foram consideradas oito áreas programáticas (AP), que são: $\mathrm{AP}$ 1, AP 2.1, $\mathrm{AP} 2.2, \mathrm{AP} 3.1, \mathrm{AP}$ 3.2, AP 3.3, AP 4, e AP 5. Cada uma destas áreas compõe-se de várias regiões administrativas. ${ }^{3}$ As áreas foram caracterizadas em termos de população total e de adolescentes; indicadores de favelização (população favelada e aumento da população favelada no período de 1980 a 1992); nível de instrução e renda do chefe da família; e média de cômodos por domicílio. Esses indicadores foram selecionados pelo fato de serem os que melhor refletem a heterogeneidade dessas áreas, descritas a seguir.

A AP 1 é a mais antiga, formada pelo centro comercial do Município e bairros próximos, e possui boas condições de saneamento. As AP 2.1 e AP

\footnotetext{
O Município do Rio de Janeiro é composto pelas seguintes regiões administrativas (cada região engloba o próprio bairro que a denomina além de bairros adjacentes: AP 1) Portuária, Centro, Rio Comprido, São Cristóvão, Paquetá e Santa Teresa; AP 2.1) Botafogo, Copacabana, Lagoa e Rocinha; AP 2.2) Tijuca e Vila Isabel; AP 3.1) Ramos, Penha, Ilha do Governador, Complexo da Maré e Complexo do Alemão; AP 3.2) Meier, Inhauma e Jacarezinho; AP 3.3) Irajá, Madureira, Anchieta e Pavuna; AP 4) Jacarepaguá e Barra da Tijuca; AP 5) Bangu, Campo Grande, Santa Cruz e Guaratiba.
}

2.2 congregam a população com o melhor padrão de vida, embora mesclada com uma população pobre residente em grandes favelas, dentre elas a Rocinha. Esta é considerada a maior favela da América Latina, com uma população de 42282 residentes, 11947 domicílios e uma área ocupada de $722480 \mathrm{~m}^{2}(14,15)$.

As AP 3.1 e AP 3.2 caracterizam-se por reunirem população com baixa escolaridade, baixa renda e elevada proporção de população favelada. A AP 3.3 e a AP 5 podem ser consideradas como aquelas que congregam as piores condições de vida do Município. No caso da AP 5 essas condições são agravadas pela carência de infraestrutura de saneamento, que abrange apenas 9\% dos domicílios. Finalmente, a AP 4, que é uma área de ocupação recente, tem uma população com boa escolaridade e renda, e acelerado processo de instalação sanitária.

A mortalidade por causas externas em todas as áreas foi destacada e detalhada em relação às principais causas: acidentes de trânsito com veículo a motor (E810-E819) e homicídios (E960-E969). A análise englobou também o subgrupo das lesões por arma de fogo de origem ignorada (acidental ou intencionalmente infligidas) (E985), devido à sua relevância para o Município do Rio de Janeiro.

As populações inter-censitárias foram estimadas pelo método aritmético, tendo como base os censos demográficos de 1980 (16) e 1991 (17). A escolha deste método deveu-se à facilidade operacional que ele oferece e ao pequeno crescimento da população no período investigado (18).

Efetuou-se ainda uma análise de séries temporais tendo em vista que esta é a técnica mais adequada para descrever o comportamento de uma variável em função do tempo. Esta técnica foi aplicada para os acidentes de trânsito e homicídios do Município, com o objetivo de observar tendência e sazonalidade, a partir do procedimento proposto por Box e Jenkins (19-21). Os três estágios da técnica foram executados: identificação, estimação e diagnóstico, embora não seja objetivo deste trabalho apresentar os 
TABELA 1. Indicadores sócio-econômicos e demográficos das áreas programáticas (AP) do Município do Rio de Janeiro

\begin{tabular}{|c|c|c|c|c|c|c|c|c|}
\hline Indicadores & AP 1 & AP 2.1 & AP 2.2 & AP 3.1 & AP 3.2 & AP 3.3 & AP 4 & AP 5 \\
\hline População de 10 a 19 anos (\%) & 15,3 & 13,1 & 14,6 & 17,7 & 16,1 & 17,6 & 17,7 & 10,3 \\
\hline Número de favelas & 57 & 26 & 25 & 86 & 82 & 102 & 103 & 92 \\
\hline Aumento da população favelada (1980-1992) (\%) & 8,0 & 20,7 & 13,7 & 15,8 & 30,8 & 49,8 & 178,3 & 79,7 \\
\hline Chefes de família com até três anos de estudo (\%) & 20,0 & 8,8 & 8,9 & 22,0 & 15,2 & 50,4 & 17,0 & 22,5 \\
\hline Chefes de família com curso universitário (\%) & 11,9 & 42,8 & 36,6 & 9,1 & 15,0 & 6,8 & 21,0 & 4,4 \\
\hline \multicolumn{9}{|l|}{ Renda média mensal do chefe de família (\%) } \\
\hline até dois salários mínimos & 41,9 & 14,7 & 18,0 & 42,2 & 34,5 & 40,7 & 32,0 & 47,6 \\
\hline acima de 15 salários mínimos & 3,6 & 28,5 & 18,8 & 3,5 & 4,9 & 1,7 & 13,0 & 1,3 \\
\hline
\end{tabular}

Fonte: IPLANRIO (14, 15); IBGE (17).

dados referentes à estimação nem ao diagnóstico dos modelos testados.

\section{RESULTADOS}

As diferentes AP analisadas no presente estudo constituem espaços sociais heterogêneos, não apenas entre si, mas também internamente, com qualidades de vida desiguais dentro de uma única AP. Este fato fica claro na tabela 1, que apresenta indicadores sócio-econômicos e demográficos do Município do Rio de Janeiro de acordo com as AP.

Conforme a tabela 1, nas AP 2.1 e AP 2.2 se encontram a maioria das pessoas com escolaridade superior, renda alta e os domicílios com maior número de cômodos. A AP 3.3 e a AP 5 são as áreas que apresentam os índices mais baixos de escolaridade. Um dado crucial que merece ser ressaltado é o crescimento da população favelada em todas as áreas programáticas na década de 80 .

\section{O perfil da mortalidade}

No Município do Rio de Janeiro, de 1980 a 1994, ocorreram 20224 mortes por todas as causas na faixa de 10 a 19 anos de idade (275 destas mortes não foram consideradas pelo presente estudo porque a AP onde ocorreram os óbitos era desconhecida). Isto significa em média 112,4 mortes por mês ou
3,7 por dia. Do total, $74,6 \%$ das vítimas tinham de 15 a 19 anos; 75,3\% eram do sexo masculino; $64,2 \%$ das mortes ocorreram em hospital. As causas externas foram responsáveis por $63 \%$ do total de mortes. As proporções de sinais e sintomas mal definidos (conforme o capítulo 16 da nona revisão da CID, que engloba as causas de morte mal definidas) passaram de 5,5\% em 1980 para 6,8\% em 1994.

A principal causa da mortalidade geral na faixa de 10 a 14 anos foram as causas externas, seguidas das neoplasias. Em terceiro lugar alternam-se as doenças dos aparelhos circulatório, respiratório e digestivo. A taxa de mortalidade geral neste grupo de idade caiu de 86,1 (em 100000 habitantes) em 1980 para 70,3 em 1994.

No grupo de 15 a 19 anos de idade, as principais causas de morte foram, de longe, as externas, seguidas das neoplasias e das doenças do aparelho circulatório. A mortalidade geral nesta faixa de idade cresceu de 169,5 (em 100000 habitantes) em 1980 para 277,5 em 1994. A distribuição da mortalidade geral e por causas externas na faixa de 10 a 19 anos, segundo AP, nos anos de 1980 a 1994, pode ser vista na tabela 2. A tabela 2 revela proporções de óbitos entre adolescentes mais altas nas AP 1, AP 3.1 e AP 5, tanto em relação à mortalidade geral quanto por causas externas.

TABELA 2. Distribuição dos óbitos por mortalidade geral e causas externas entre adolescentes de 10 a 19 anos por áreas programáticas (AP), Município do Rio de Janeiro, 1980 a 1994

\begin{tabular}{|c|c|c|c|c|}
\hline \multirow[b]{2}{*}{ AP } & \multicolumn{2}{|c|}{ Mortalidade geral $^{\mathrm{a}}$} & \multicolumn{2}{|c|}{ Causas externas $^{b}$} \\
\hline & No. & $\%$ & No. & $\%$ \\
\hline 1 & 4177 & 20,9 & 2019 & 16,1 \\
\hline 2.1 & 1775 & 8,9 & 989 & 7,9 \\
\hline 2.2 & 1687 & 8,5 & 709 & 5,7 \\
\hline 3.1 & 4459 & 22,4 & 3067 & 24,5 \\
\hline 3.2 & 1520 & 7,6 & 1124 & 9,0 \\
\hline 3.3 & 1918 & 9,6 & 1479 & 11,8 \\
\hline 4 & 1475 & 7,4 & 953 & 7,6 \\
\hline 5 & 2938 & 14,7 & 2174 & 17,4 \\
\hline Total & 19949 & 100,0 & 12514 & 100,0 \\
\hline
\end{tabular}

Fonte: Secretaria Estadual de Saúde do Rio de Janeiro.

aExcluídos 275 óbitos por todas as causas com AP ignorada.

bExcluídos 205 óbitos por causas externas com AP ignorada. 


\section{Mortes violentas: magnitude e impacto}

No período de 1980 a 1994 morreram, por causas externas, 12719 adolescentes de 10 a 19 anos no município investigado - 70,7 ao mês ou 2,4 ao dia - sendo $86,7 \%$ deles do sexo masculino (205 destas mortes não foram consideradas pelo presente estudo porque a AP onde ocorreram os óbitos era desconhecida). Do total de óbitos, $82 \%$ encontravam-se na faixa etária dos 15 aos 19 anos; 49,9\% das mortes ocorreram em hospital, 33,9\% em via pública e 2,4\% em domicílios; $79,7 \%$ das mortes foram atestadas pelo Instituto Médico Legal (IML).

Na tabela 3 encontram-se as taxas de mortalidade por causas externas, na faixa de 10 a 19 anos, distribuídas segundo AP e sexo, em anos selecionados. Conforme a tabela 3, as taxas de mortalidade por causas externas são mais elevadas para o sexo masculino em todas as áreas. Este fato é mais intenso na faixa de 15 a 19 anos. As mortes violentas nesta faixa etária, em 1980, representavam $62,2 \%$ da taxa de mortalidade geral; em 1994 aumentaram para $72,7 \%$ dessa taxa.

Para os adolescentes de 10 a 19 anos do Município como um todo, a tabela 3 revela que as taxas de mortalidade por causas externas no sexo masculino cresceram $50,7 \%$. No sexo feminino o crescimento foi de $23,0 \%$ entre os anos de 1980 e 1994. As AP 1 e AP 3.1 se destacam com as taxas mais elevadas de mortalidade por causas externas ao longo de todo o período. A AP 3.2 apresenta o maior crescimento $(215 \%)$

TABELA 3. Taxas ${ }^{\mathrm{a}}$ de mortalidade por causas externas entre adolescentes de 10 a 19 anos, Município do Rio de Janeiro, 1980 a 1994

\begin{tabular}{llrrrrrrrrr}
\hline Ano & Sexo & AP 1 & AP 2.1 & AP 2.2 & AP 3.1 & AP 3.2 & P 3.3 & AP 4 & AP 5 & Município \\
\hline 1980 & Masc & 287,4 & 124,6 & 131,9 & 224,7 & 81,6 & 64,8 & 92,2 & 78,0 & 120,5 \\
& Fem & 77,0 & 28,1 & 25,2 & 49,1 & 10,7 & 13,9 & 24,1 & 12,8 & 25,7 \\
1982 & Masc & 274,6 & 83,5 & 115,1 & 183,5 & 80,9 & 55,2 & 93,2 & 54,6 & 100,2 \\
& Fem & 72,2 & 21,3 & 41,5 & 37,1 & 10,9 & 5,9 & 7,7 & 17,8 & 22,1 \\
1984 & Masc & 456,5 & 121,4 & 147,3 & 232,1 & 76,3 & 89,5 & 81,7 & 57,3 & 128,3 \\
& Fem & 104,5 & 30,2 & 22,7 & 42,8 & 18,5 & 7,1 & 14,7 & 1,7 & 22,1 \\
1986 & Masc & 436,8 & 124,3 & 116,4 & 245,7 & 114,2 & 96,9 & 147,0 & 79,1 & 143,7 \\
& Fem & 108,2 & 37,5 & 19,7 & 45,8 & 7,5 & 9,6 & 23,5 & 6,7 & 24,3 \\
1988 & Masc & 580,3 & 160,3 & 148,9 & 279,3 & 123,7 & 116,9 & 113,8 & 133,7 & 176,6 \\
& Fem & 76,0 & 17,3 & 20,0 & 32,1 & 15,4 & 7,3 & 18,0 & 18,0 & 21,1 \\
1990 & Masc & 602,2 & 161,8 & 235,3 & 298,9 & 185,4 & 192,5 & 159,7 & 135,0 & 209,4 \\
& Fem & 58,1 & 29,3 & 23,7 & 35,1 & 15,7 & 7,4 & 32,5 & 6,4 & 22,4 \\
1992 & Masc & 581,5 & 118,9 & 136,2 & 187,2 & 155,8 & 157,5 & 122,1 & 126,2 & 165,3 \\
& Fem & 81,9 & 28,2 & 27,5 & 25,4 & 8,0 & 17,6 & 10,4 & 10,1 & 19,7 \\
1994 & Masc & 632,9 & 160,1 & 119,0 & 231,0 & 256,9 & 142,0 & 101,5 & 126,9 & 181,6 \\
& Fem & 130,1 & 71,3 & 24,5 & 41,2 & 38,9 & 22,9 & 18,1 & 19,7 & 31,6 \\
\hline
\end{tabular}

Fonte: Secretaria Estadual de Saúde do Rio de Janeiro. a Taxas por 100000 habitantes.

da mortalidade por causas externas entre os anos inicial e final. De modo geral, nas demais áreas percebe-se o crescimento da mortalidade por causas externas com um pico entre os anos de 1988 e 1990, seguido de decréscimo nos anos seguintes (com exceção das AP 2.1 e AP 3.2 cujas taxas cresceram em 1994).

A tabela 4 mostra a magnitude das causas de morte externas em relação à mortalidade geral, bem como as proporções de acidentes de trânsito, homicídios e mortes por arma de fogo de origem ignorada dentro do grupo de mortes por causas externas. De acordo com a tabela 4 , as causas externas assumem maior importância na faixa de 15 a 19 anos e no sexo mascu- lino. Os acidentes de trânsito preponderam na faixa de 10 a 14 anos, enquanto os homicídios são mais freqüentes na faixa de 15 a 19 anos.

A seguir, as mortes por acidentes de trânsito e homicídios serão analisadas em detalhe, pelo fato destas duas causas específicas de morte serem as mais freqüentes entre as causas externas. As lesões por arma de fogo de origem ignorada serão analisadas juntamente com os homicídios.

\section{Mortes no trânsito}

Dentre os 1851 adolescentes de 10 a 19 anos vítimas do trânsito no Rio de Janeiro entre 1980 e 1994, 72,1\% eram

TABELA 4. Distribuição da mortalidade a por causas segundo faixa etária e sexo, Município do Rio de Janeiro, 1980 a 1994

\begin{tabular}{|c|c|c|c|c|c|c|c|c|c|c|c|}
\hline \multirow[b]{2}{*}{ Idade (anos) } & \multirow[b]{2}{*}{ Sexo } & \multicolumn{2}{|c|}{ Causas externas } & \multicolumn{2}{|c|}{$\begin{array}{l}\text { Acidentes } \\
\text { de trânsito }\end{array}$} & \multicolumn{2}{|c|}{ Homicídios } & \multicolumn{2}{|c|}{$\begin{array}{l}\text { Arma de fogo de } \\
\text { origem ignorada }\end{array}$} & \multicolumn{2}{|c|}{ Todas as causas } \\
\hline & & No. & $\%$ & No. & $\%$ & No. & $\%$ & No. & $\%$ & No. & $\%$ \\
\hline \multirow[t]{2}{*}{10 a 14} & Masc & 1729 & 13,6 & 473 & 25,6 & 192 & 6,3 & 201 & 5,3 & 3295 & 16,3 \\
\hline & Fem & 560 & 4,4 & 199 & 10,8 & 53 & 1,7 & 52 & 1,4 & 1831 & 9,1 \\
\hline \multirow[t]{2}{*}{15 a 19} & Masc & 9297 & 73,1 & 862 & 46,5 & 2652 & 86,5 & 3369 & 88,9 & 11925 & 58,9 \\
\hline & Fem & 1131 & 8,9 & 317 & 17,1 & 167 & 5,5 & 168 & 4,4 & 3167 & 15,7 \\
\hline 10 a 19 & - & 12717 & 100,0 & 1851 & 100,0 & 3064 & 100,0 & 3790 & 100,0 & 20218 & 100,0 \\
\hline
\end{tabular}

Fonte: Secretaria Estadual de Saúde do Rio de Janeiro.

axclui óbitos com idade ou sexo ignorados. 
FIGURA 1. Taxas ${ }^{\mathrm{a}}$ de mortalidade por acidentes de trânsito entre adolescentes de 10 a 19 anos, Município do Rio de Janeiro e áreas programáticas, 1980 a 1994

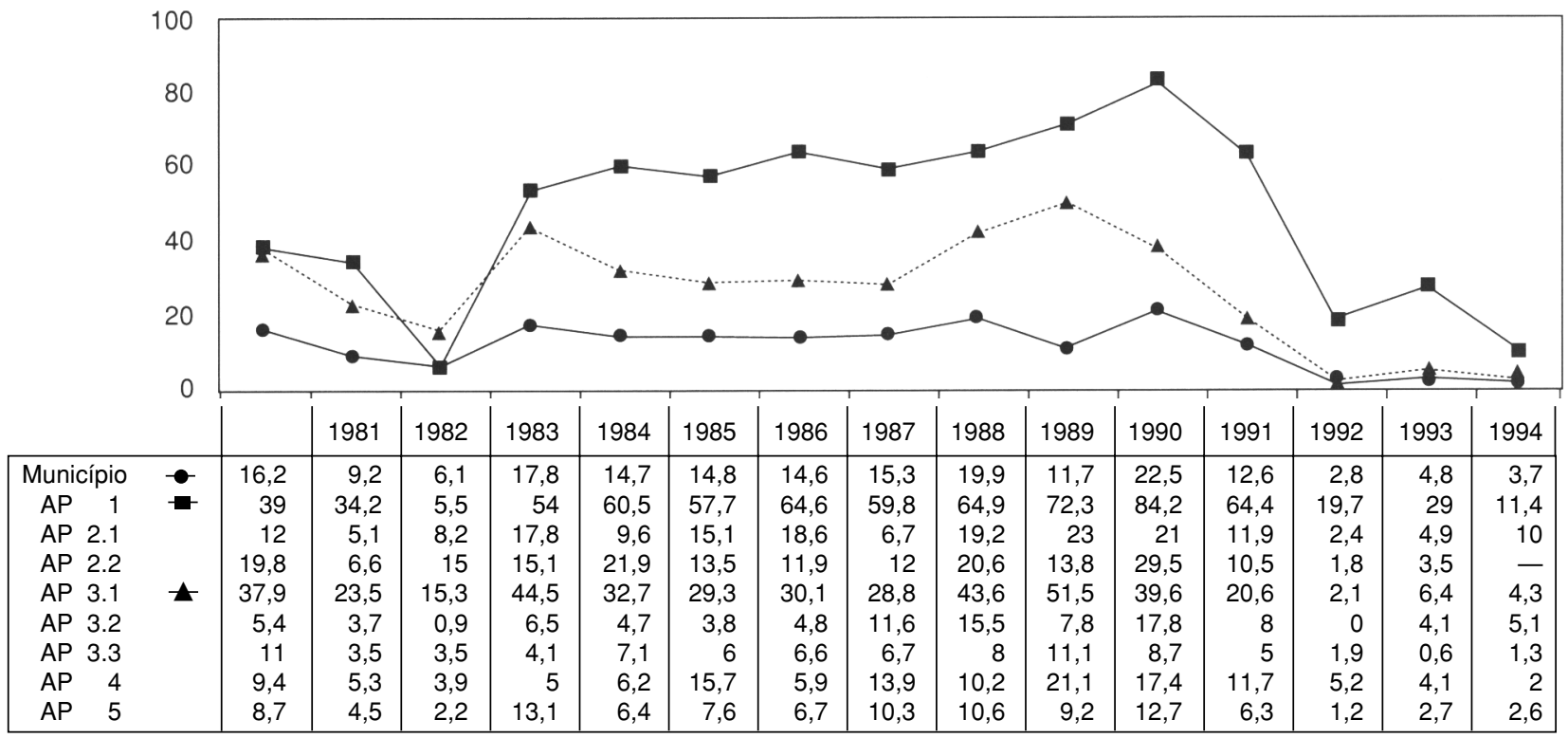

Fonte: Secretaria Estadual de Saúde do Rio de Janeiro.

a Taxas por 100000 habitantes.

do sexo masculino e $63,7 \%$ encontravam-se na faixa de 15 a 19 anos; $83,9 \%$ haviam nascido no próprio Estado do Rio de Janeiro. O IML atestou 75,2\% dessas mortes, que ocorreram em $78,9 \%$ em hospital, seguidas de 18,2\% em via pública. Muitos desses adolescentes $(68,5 \%)$ eram estudantes (em sua maioria cursando o primeiro grau, em torno de 8 anos de estudo).

As taxas anuais de mortalidade por acidentes de trânsito na faixa de 10 a 19 anos, para o conjunto do Município e por $\mathrm{AP}$, encontram-se na figura 1 . Entre 1980 e 1994 as taxas de mortalidade por acidentes de trânsito para $o$ Município do Rio de Janeiro decresceram $77,2 \%$, de 16,2 para 3,7 (em 100000 habitantes) entre 10 e 19 anos. Nos anos investigados, o principal tipo de acidente de trânsito, nesta faixa de idade, foram os atropelamentos $(61,6 \%)$, seguidos de óbitos por acidentes de trânsito não especificados $(23,7 \%)$. Nos anos de 1990 e 1994 cerca de metade dos acidentes de trânsito ocorreram no final de semana.

A análise de séries temporais revelou uma tendência decrescente na mortalidade por acidentes de trânsito, embora esses óbitos não tenham apresentado nenhuma distribuição sazonal. A figura 2 apresenta o diagrama de dispersão das variáveis, onde se traçou uma reta para visualizar essa tendência.
Como mostra a tabela 5, parte das vítimas de acidentes de trânsito não residiam na área onde o acidente aconteceu. Isto é particularmente significativo nas AP 1 e AP 3.1, que apresentaram as maiores proporções de óbitos

FIGURA 2. Dispersão das taxas a de mortalidade por acidentes de trânsito entre adolescentes de 10 a 19 anos, Município do Rio de Janeiro, 1980 a 1994

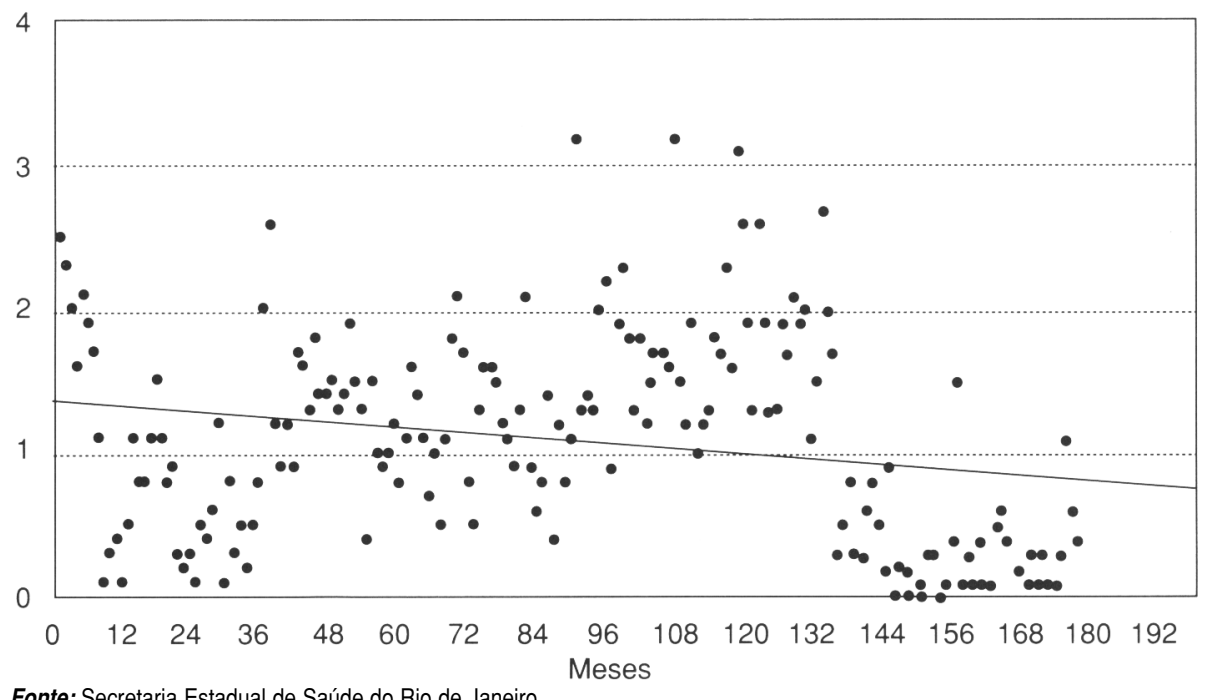

Fonte: Secretaria Estadual de Saúde do Rio de Janeiro.

a Taxas por 100000 habitantes. 
TABELA 5. Proporção de óbitos por acidentes de trânsito entre adolescentes de 10 a 19 anos, segundo locais de ocorrência e residência por áreas programáticas (AP), Rio de Janeiro, 1980 a 1994

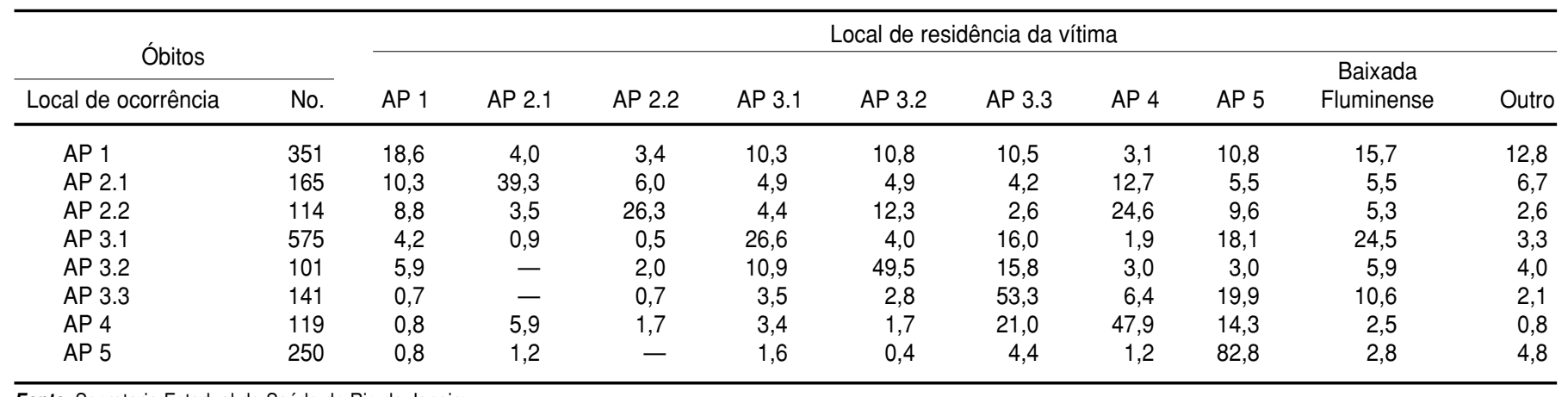

Fonte: Secretaria Estadual de Saúde do Rio de Janeiro.

de residentes em outras localidades, especialmente em municípios que fazem parte da Baixada Fluminense, região localizada na periferia do Município do Rio de Janeiro. Este fenômeno também pôde ser observado nas AP 2.1 e AP 2.2. No entanto, neste caso, muitas das vítimas residiam no Município do Rio e eram provenientes principalmente da AP 4. As demais áreas registraram significativos percentuais de óbitos de residentes da própria área.

\section{Mortes por homicídio}

De 1980 a 1994, 6856 adolescentes de 10 a 19 anos foram assassinados no Município do Rio de Janeiro. Isto significa uma média de 37 óbitos por mês, ou 1,2 por dia. O sexo mais atingido foi o masculino $(93,6 \%)$ e a faixa etária de maior incidência foi a de 15 a 19 anos $(92,7 \%) ; 82,4 \%$ das vítimas eram nascidas no Rio de Janeiro. Os óbitos foram atestados pelo IML em $81,3 \%$ dos casos; $36,2 \%$ deles ocorreram em hos- pital, $44,7 \%$ em via pública e $2,9 \%$ em domicílios. A ocupação de estudante foi encontrada para $43,3 \%$ das vítimas, em sua maioria cursando o primeiro grau (8 anos de estudo).

A taxa de mortalidade por homicídios na faixa de 10 a 19 anos cresceu $121,6 \%$ entre 1980 e 1994 para o Município do Rio de Janeiro. Conforme a figura 3, este índice subiu de 29,6 (em 100000 habitantes) em 1980 para 65,6 em 1994. A figura 3 revela também que as $\mathrm{AP} 1$ e AP 3.1 destacam-se das

FIGURA 3. Taxas ${ }^{a}$ de mortalidade por homicídios entre adolescentes de 10 a 19 anos, Município do Rio de Janeiro e áreas programáticas, 1980 a 1994

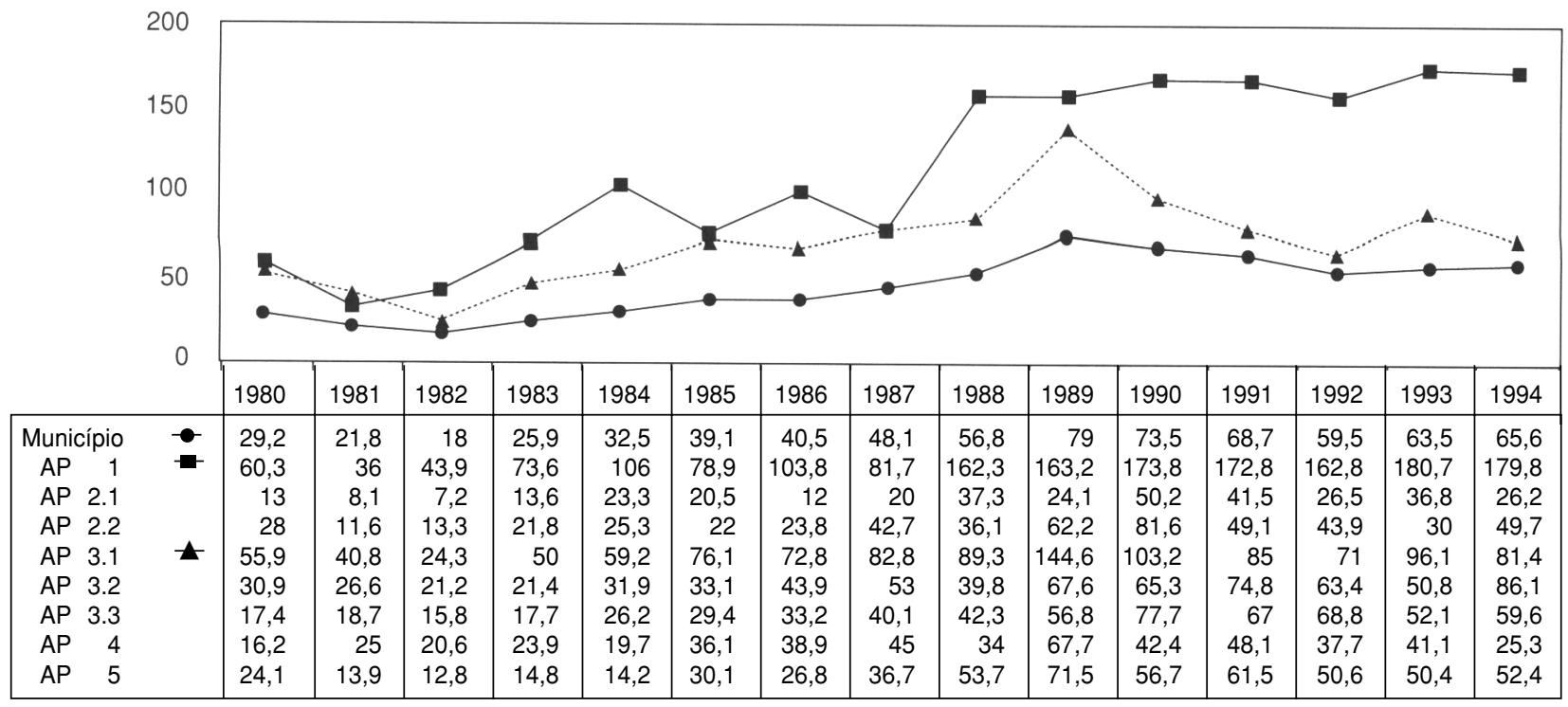

Fonte: Secretaria Estadual de Saúde do Rio de Janeiro.

a Taxas por 100000 habitantes. 
demais com as mais elevadas taxas de mortalidade por homicídios. Embora as taxas oscilem no período, há um padrão de crescimento em todas as áreas. Para esta causa específica não se observa, como para o conjunto das causas externas e para os acidentes de trânsito, a diminuição acentuada a partir do ano de 1991. Pelo contrário, percebe-se que nos anos 90 as taxas de mortalidade por homicídios encontram-se em patamares muito superiores aos da década de 80 .

Os principais tipos de homicídios identificados ao longo dos anos investigados distribuem-se da seguinte forma: $95,6 \%$ foram perpetrados com armas de fogo; $0,3 \%$ por estrangulamento e enforcamento; $0,6 \%$ com arma branca (faca, punhal); e 3\% foram considerados homicídios não especificados. Não se observou a ocorrência de sazonalidade dessas mortes em relação ao dia da semana.

A análise de séries temporais revelou a presença de uma tendência crescente da mortalidade por homicídios, e a ausência de efeitos sazonais no período investigado. A figura 4 apresenta o diagrama de dispersão das variáveis, onde se traçou uma reta com o intuito de visualizar melhor a tendência observada na análise.

A tabela 6 mostra a distribuição proporcional dos homicídios, segundo local de ocorrência do óbito e de residência da vítima. Conforme a tabela 6 , a maioria dos homicídios ocorridos nas diferentes áreas vitimaram os pró-

FIGURA 4. Dispersão das taxas ${ }^{\mathrm{a}}$ de mortalidade por homicídios entre adolescentes de 10 a 19 anos, Município do Rio de Janeiro, 1980 a 1994

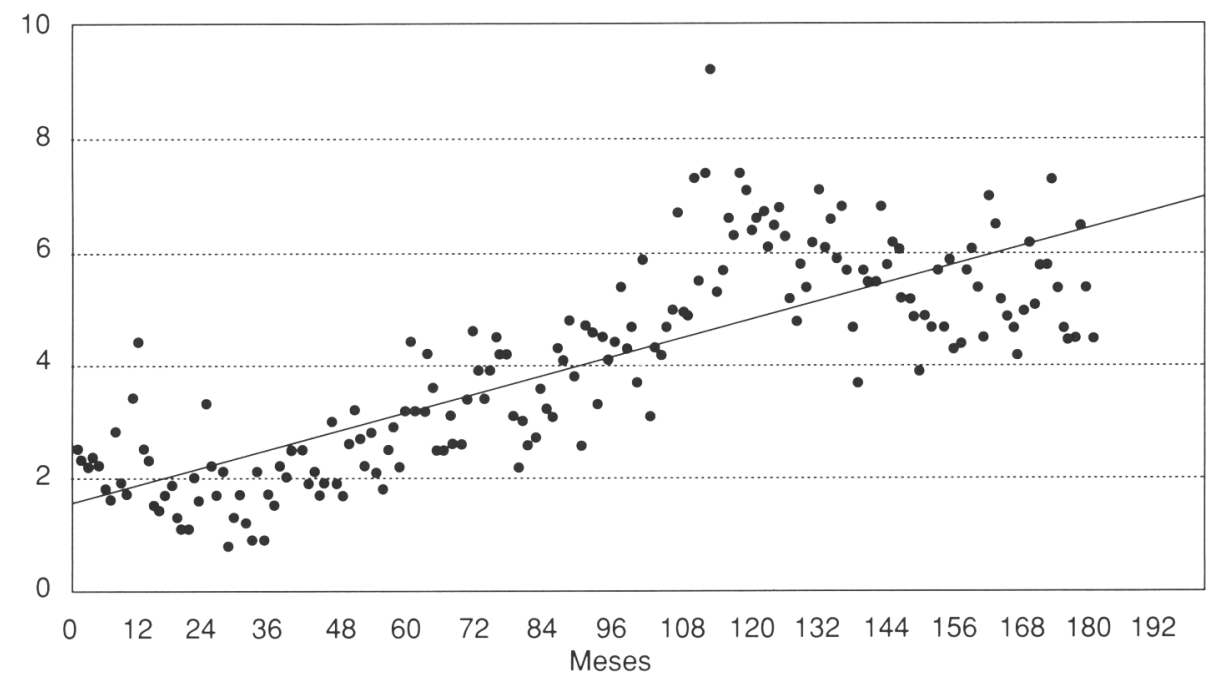

Fonte: Secretaria Estadual de Saúde do Rio de Janeiro.

a Taxas por 100000 habitantes.

prios residentes. A AP 1 é uma exceção, pois nela foram elevados os percentuais de mortes de moradores da AP 3.1, AP 5 e de outros municípios. A AP 3.1 e AP 3.3 também apresentaram consideráveis proporções de mortes de residentes de outros municípios.

\section{DISCUSSÃO}

A elevada mortalidade por violência entre adolescentes do Município do Rio de Janeiro é inadmissível. Tratamse de mortes de pessoas muito jovens que sequer atingiram a vida adulta. $\mathrm{O}$ mais preocupante é que a violência no país tem incidido cada vez mais intensamente sobre grupos cada vez mais jovens. O estudo de Souza (7), comparando os anos de 1980 e 1990, mostra que dentre todas as faixas etárias, o grupo de 10 a 14 anos teve o maior crescimento proporcional de mortes por homicídios $(79,5 \%)$, seguido da faixa de 15 a 19 anos (45,3\%).

Nos Estados Unidos, Yunes (3) observou um incremento das taxas de homicídios nessas idades, nos anos de 1979 e 1989. Segundo este autor, o

TABELA 6. Proporção de óbitos por homicídio entre adolescentes de 10 a 19 anos, segundo locais de ocorrência e residência por áreas programáticas (AP), Rio de Janeiro, 1980 a 1994

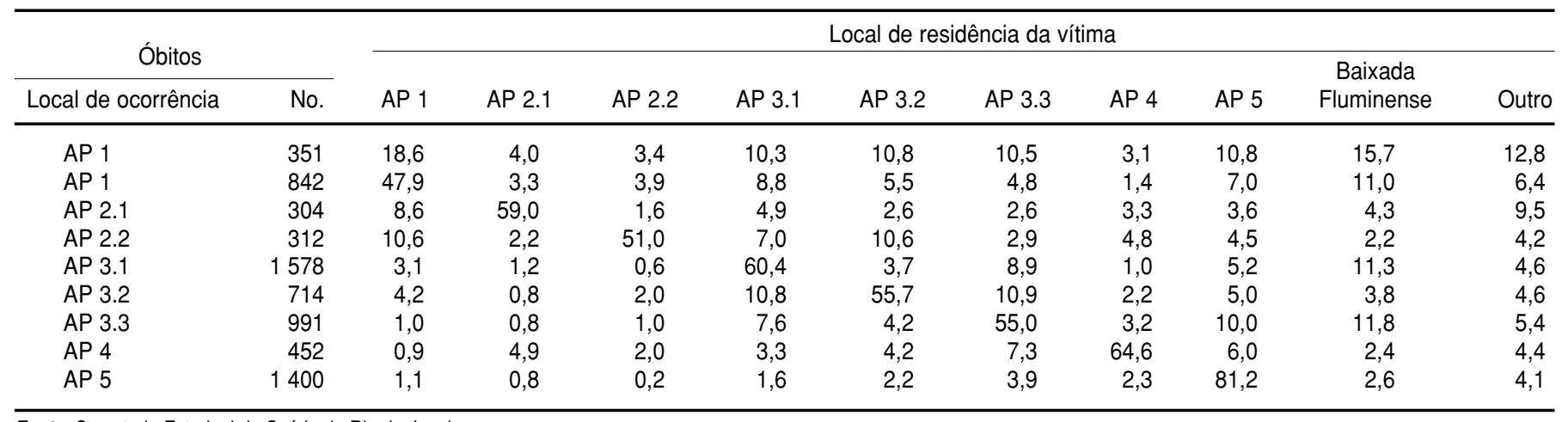

Fonte: Secretaria Estadual de Saúde do Rio de Janeiro. 
crescimento foi da ordem de $59 \%$ na faixa de 10 a 14 anos e de $37 \%$ no grupo de 15 a 19 anos. Ele contrasta a elevação ocorrida entre adolescentes com a diminuição em $7 \%$ das taxas de homicídios na população em geral.

Souza (7) refere para o Brasil, no ano de 1988 , a taxa de 1,7 mortes por homicídio em cada 100000 habitantes de 10 a 14 anos. Para este mesmo ano e grupo etário a taxa encontrada no presente estudo para o Rio foi de 6,6. Na faixa de 15 a 19 anos a taxa observada por Souza (7) para o Brasil foi de 20,8, enquanto que para o Rio o presente estudo revelou uma taxa assustadoramente mais elevada - 106,8. Mesmo considerando que neste trabalho os dados para homicídios possam estar superestimados em relação ao país (pois incluem as lesões de origem ignorada por arma de fogo), as taxas do Rio de Janeiro são extremamente mais altas. Mesmo se as lesões de origem ignorada por arma de fogo fossem excluídas do grupo dos homicídios ainda assim o Rio de Janeiro apresentaria taxas maiores do que as do Brasil, onde este grupo de lesões é relativamente baixo.

Além disso, a exclusão das lesões de origem ignorada por arma de fogo subestimaria enormemente as taxas por essa causa específica. Estudos como os de Mello Jorge (22), Souza (23, 24) e Lait (25), que analisaram detidamente as falhas no preenchimento da causa básica do óbito pelo IML, sugerem que a maioria dos óbitos classificados no grupo das lesões ignoradas (E980-E989) são, na verdade, mortes por acidentes de trânsito e homicídios não esclarecidos. $\mathrm{Na}$ presente análise observou-se que, no Município do Rio de Janeiro, existe grave falha quanto ao esclarecimento da causa básica do óbito. Isto pode ser constatado pelo fato de $47,1 \%$ das mortes por causas externas, entre 1980 e 1994, na faixa de 10 a 19 anos, terem sido incluídas no grupo das lesões ignoradas. Além disso, verificaram-se também os seguintes problemas: 1) os homicídios (E960-E969) passaram de 265 casos em 1980 para 305 casos em 1994; 2) o grupo das lesões por arma de fogo ignoradas (E985) cresceu de 13 casos em 1980 para 310 casos em 1994. Para o período, este grupo constitui $63,2 \%$ de todas as lesões ignoradas (E980-E989).

Portanto, considerar o subgrupo E985 como homicídio garante um erro mínimo, quando comparado ao sub-registro dos homicídios oficialmente declarados. É por isto que na análise referente aos homicídios as taxas de mortalidade são apresentadas incluindo-se as lesões por arma de fogo do tipo ignorado.

Ao comparar as mortes por homicídios no Rio de Janeiro com países cujas taxas são consideradas altas, observase que neste Município o risco dos adolescentes é muito maior do que, por exemplo, na Colômbia, onde as taxas, em 1988, foram de 4,3 em 100000 habitantes entre 10 e 14 anos e de 50,2 entre jovens de 15 a 19 anos (3). O mesmo ocorre em relação aos Estados Unidos, no mesmo ano, onde as taxas foram de 1,6 e 10,3, respectivamente (3). Os resultados do presente estudo revelam que a taxa de homicídios entre adolescentes de 15 a 19 anos do Rio de Janeiro é cerca de duas vezes maior do que a da Colômbia e dez vezes a dos Estados Unidos.

Comparados aos acidentes de trânsito, os homicídios apresentam a característica peculiar de vitimizar, preferencialmente, os próprios moradores da área. É interessante também notar que as lesões por arma de fogo do tipo ignorado distribuem-se de modo semelhante aos homicídios.

Outro dado que chama a atenção neste estudo é a diminuição dos acidentes de trânsito a partir de 1991. Contudo, é provável que esta diminuição seja um artifício decorrente da deterioração da qualidade da informação, já que nenhuma medida de prevenção foi implementada de modo a justificar o decréscimo observado.

No período investigado, percebeuse, em paralelo à queda do número de acidentes de trânsito, uma elevação do grupo não especificado (E988.9) das lesões ignoradas (E980-E989). É, portanto, provável que boa parte deste grupo seja constituída por acidentes de trânsito que não foram esclarecidos.

Os dados sobre acidentes de trânsito encontrados neste trabalho apontam para a expressiva magnitude dessa causa de mortes entre os adolescentes do Rio de Janeiro. Para o Brasil, Mello Jorge (26), em 1987, encontrou a taxa de mortalidade de 7,1 (em 100000 habitantes) na faixa de 10 a 14 anos. No mesmo ano, a taxa encontrada para o Rio de Janeiro foi de 11,2. No grupo de 15 a 19 anos a taxa para o Brasil foi de 15,1 , enquanto no Rio ela foi de 19,4. Mello Jorge (26) destaca também as elevadas taxas de mortalidade por acidentes de trânsito, no Município do Rio, durante toda a década de 80 . Nos Estados Unidos (3), em 1987, a taxa para o grupo de 10 a 14 anos foi a mesma do Brasil $(7,1)$ enquanto a taxa para o grupo de 15 a 19 anos foi maior naquele país $(27,6)$

No Brasil, assim como no Rio de Janeiro, o principal tipo de morte por acidente de trânsito é o atropelamento, diferente dos Estados Unidos, onde grande parte dessa mortalidade é por colisão. No entanto, as poucas medidas de prevenção adotadas no Brasil favorecem o motorista, pelo fato das colisões serem o tipo de acidente mais freqüente no total das ocorrências de trânsito. $\mathrm{O}$ impacto deste tipo de medida afeta diretamente a morbidade. Medidas preventivas que pretendam diminuir a mortalidade devem considerar os fatores envolvidos especificamente com os atropelamentos, cujas principais vítimas são os pedestres.

O objetivo maior deste trabalho foi efetuar uma análise que discriminasse áreas com riscos diferenciados de violência contra adolescentes. Tais áreas foram identificadas apesar das dificuldades geradas pela heterogeneidade interna em cada área programática, que fazem da vigilância à saúde no nível proposto uma tarefa (ainda) difícil. Desse modo, o estudo aponta para a necessidade de delimitar áreas ainda menores de análise. Acredita-se que tal abordagem reforçaria a prática da vigilância em níveis locais de saúde.

Neste estudo identificou-se a necessidade de medidas preventivas de vigilância à saúde, especificamente contra a violência, que vitima adolescentes em todas as áreas do Município. Porém, tais ações deveriam priorizar especialmente as AP 1 e AP 3.1 devido à intensidade e à magnitude dos acidentes de trânsito e dos homicídios que nelas 
ocorrem. A AP 1 tem a menor população vivendo em casas muito pequenas e com baixa renda mensal, e o maior percentual de favelados. Observou-se que esta foi a área que apresentou maior freqüência de óbitos de moradores de outros municípios, principalmente da Baixada Fluminense. A Baixada Fluminense é uma área periférica à capital, constituída por sete municípios que abrigam uma população de baixa renda e apresentam altas taxas de mortalidade por violência e precária infra-estrutura de serviços de saúde. Portanto, os óbitos da AP 1 congregam os agravos devidos à grande circulação de pessoas no centro da cidade e os óbitos decorrentes da procura pelos hospitais desta área por habitantes vitimados em outros municípios.

Por sua vez, a AP 3.1 encontra-se entre as áreas com os piores indicadores sócio-econômicos do Município (embora as AP 3.3 e AP 5 também apresentem indicadores econômicos tão preocupantes quanto os da AP 3.1). A AP 3.1 possui o maior número de pessoas faveladas (cerca de 247 500) e nela localizam-se vários grupos ligados ao narcotráfico. Também ali a maioria das vítimas é de não residentes, especialmente de moradores da Baixada Fluminense. Mais uma vez, o afluxo de pessoas de outras áreas deve-se, em grande medida, à procura dos hospitais que se situam nesta área e estão geograficamente próximos à Baixada. Além disto, a AP 3.1 é recortada por uma avenida de intenso tráfego, o que acentua o risco de ocorrência de acidentes de trânsito. Aliada a estas características, constata-se a deficiênca dos serviços de saúde dos municípios vizinhos ao Rio de Janeiro, que não estão aparelhados adequadamente ou inexistem naquelas localidades, levando a uma superlotação dos hospitais da capital.

Contrariamente ao que se poderia supor, as AP 3.3 e AP 5, que apresentam os piores indicadores sócio-econômicos do Município do Rio de Janeiro, não são as áreas onde se encontram as maiores taxas de mortes por homicídios. Este fato confirma a teoria de que não é apenas a pobreza que explica a ocorrência da violência, mas um conjunto de fatores associados. No caso da
AP 5, a persistência de um padrão de vida ainda rural pode, possivelmente, estar atuando como fator protetor contra a intensificação da violência nesta área; já em relação à AP 3.3 ressalta-se a necessidade de medidas preventivas contra a violência, tendo em vista que os dados da Secretaria de Polícia Civil (27) apontam esta como sendo a área de maior violência do Município, o que foi confirmado neste trabalho.

Por outro lado, o padrão de mortalidade por violência apresentado na AP 2.1 indica ser esta a área com o menor risco de mortes por homicídios e o maior risco para acidentes de trânsito. Este é um dado coerente com as características da área, tendo em vista que a mesma congrega as melhores condições de vida, com grande circulação de automóveis.

\section{CONCLUSÕES}

Este estudo possibilitou conhecer os diferentes tipos de risco em distintos espaços sociais do Rio de Janeiro, além de revelar a inoperância e a carência de serviços de saúde em determinadas áreas do próprio Município e em áreas periféricas deste. Seus achados podem ser valiosos para subsidiar a reorientação de ações e políticas públicas de saúde.

No que se refere aos profissionais envolvidos com o tema da violência, especialmente nos serviços de saúde e na segurança pública, destaca-se a necessidade de treinamento e conscientização para que os mesmos possam ser mais aptos e atentos ao diagnóstico dos eventos violentos. Uma caracterização mais adequada dos casos sem dúvida contribuiria para a maior fidedignidade nas estatísticas oficiais. Parte desta tarefa cabe, especificamente, aos médicos legistas, à medida em que passem a preencher adequadamente a declaração de óbito, indicando claramente a causa básica da morte, e aos policiais, que precisam investigar melhor as mortes por causas externas e para isso necessitam de melhores condições de trabalho. Vale ressaltar que tais medidas específicas deverão estar situadas em um contexto mais amplo de reestruturação político-administra- tiva das instituições envolvidas, o que, em última instância, significa a adoção de novas políticas sociais.

Ao adotar os preceitos da vigilância à violência, a partir dos achados deste estudo, deve-se atentar para as estruturas e dinâmicas próprias e heterogêneas de cada área programática, às quais o sistema de saúde deve contemplar com políticas sanitárias preventivas, coerentes com as suas necessidades e, sobretudo, descentralizadas. Em termos epidemiológicos, é importante pensar em estruturar sistemas locais de informação, atualizados e fidedignos, visando a tomada de decisão e ação rápidas e eficazes. A redefinição das prioridades e a redistribuição dos serviços deve ser efetuada em função da demanda. Isto, sem dúvida, evitaria grande parcela das mortes ocorridas no percurso e na peregrinação em busca de atendimento médico e desobstruiria os hospitais da capital, já assoberbados pelo atendimento aos residentes do Município.

A existência de serviços de emergência eficientes reduziria a elevada mortalidade provocada por acidentes e homicídios. Infelizmente, na última década vários serviços públicos deste tipo, no país e particularmente no Rio de Janeiro, foram fechados e desativados pelos administradores de saúde em função da crônica crise deste setor nas duas últimas décadas.

A própria complexidade e especificidade das causas externas de morte sugerem que a atuação preventiva do setor de saúde não pode se restringir a serviços de atendimento. É preciso que suas políticas se dirijam a etapas anteriores, integrando o setor de saúde a outros setores e instituições. Especialmente em relação ao Rio de Janeiro, o combate ao crime organizado, a diminuição das desigualdades sociais, a melhoria do sistema educacional, seriam medidas urgentes a serem adotadas para evitar o quadro lastimável de violência ao qual a sociedade organizada precisa responder.

Agradecimento. Agradecemos a Angela Cascão pelo fornecimento dos dados e pelos valiosos esclarecimentos. 


\section{REFERÊNCIAS}

1. Souza ER, Minayo MCS. O impacto da violência social na saúde pública do Brasil. Em: Minayo MCS, org. Os muitos Brasis: saúde e população na década de 80. São Paulo: HUCITEC; 1995: 87-116.

2. Vermelho LL. Mortalidade de jovens: análise do período de 1930 a 1991: a transição epidemiológica para a violência. São Paulo: Faculdade de Saúde Pública da Universidade de São Paulo; 1994.

3. Yunes J, Rajs D. Tendencia de la mortalidad por causas violentas en la población general y entre los adolescentes y jovenes de la Región de las Américas. Cad Saude Publica 1994; 10(supl 1):88-125.

4. Minayo MCS, Souza ER. Violência para todos. Cad Saude Publica 1993;9(1):65-78.

5. Organização Mundial da Saúde. Manual da classificação estatística internacional de doenças, lesões e causa de óbitos. Nona revisão, 1975. São Paulo: Centro de Classificações de Doenças em Português; 1978.

6. Reichenhein ME, Werneck GL. Anos potenciais de vida perdidos no Rio de Janeiro, 1990: as mortes violentas em questão. Cad Saude Publica 1994;10(supl 1):188-198.

7. Souza ER. Homicídios no Brasil: o grande vilão da saúde pública na década de 80 . Cad Saude Publica 1994;10(supl 1):45-60.

8. Assis SG, Souza ER. Morbidade por violência em crianças e adolescentes no Município do Rio de Janeiro. J Pediatr (Rio J) 1995;71(6): 303-312.

9. Dever GEA. A epidemiologia na administração dos serviços de saúde. São Paulo: PROAHSA/ Pioneira; 1988
10. Hartz ZMA. A vigilância epidemiológica da mortalidade infantil: uma contribuição à planificação dos programas de saúde da mulher e da criança [mimeografado]. Apresentado na Oficina de Trabalho sobre Vigilância à Saúde, patrocinada pela Organização Pan-Americana da Saúde, Natal, novembro, 1990.

11. Hartz ZMA. O desafio da epidemiologia. Em: Reunião do CENEPI, João Pessoa, junho de 1992.

12. Becker RA et al. Perfis de saúde. Brasília: Ministério da Saúde/DNE; 1989.

13. Organização Mundial da Saúde. Classificação estatística internacional de doenças e problemas relacionados à saúde. Décima revisão. São Paulo: Centro de Classificação de Doenças em Português; 1996.

14. Instituto de Planejamento Municipal (IPLANRIO). Anuário Estatístico da Cidade do Rio de Janeiro, 1993/1994. Rio de Janeiro: IPLANRIO; 1995.

15. Instituto de Planejamento Municipal (IPLANRIO). Favelas cariocas: alguns dados estatísticos. Rio de Janeiro: IPLANRIO; 1993.

16. Instituto Brasileiro de Geografia e Estatística (IBGE). Censo demográfico de 1980. Rio de Janeiro: IBGE; 1983

17. Instituto Brasileiro de Geografia e Estatística (IBGE). Censo demográfico de 1991. Rio de Janeiro: IBGE; 1994

18. Klein $\mathrm{CH}$. Mortes no trânsito do Rio de Janeiro, Brasil. Cad Saude Publica 1994;10(supl 1):168-176.

19. Montgomery DC. Forecasting and time series analysis. New York: McGraw-Hill; 1990.
20. Mabert VA. An introduction to short term forecasting using the Box-Jenkins methodology. Georgia: AIIE Monograph series; 1975.

21. Morettin PA, Toloi CMC. Previsão de séries temporais. São Paulo: Atual; 1985.

22. Mello Jorge MHP. Situação atual das estatísticas oficiais relativas à mortalidade por causas externas. Rev Saude Publica 1990;24(3):217-223.

23. Souza ER. Violência velada e revelada: estudo epidemiológico da mortalidade por causas externas em Duque de Caxias, Rio de Janeiro. Cad Saude Publica 1993;9(1):48-64.

24. Souza ER. O reflexo da violência na mortalidade da Baixada Fluminense - Brasil [relatório final de pesquisa]. Rio de Janeiro: ENSP/ FIOCRUZ; 1992.

25. Lait LCF. Estimativa da mortalidade por homicídios no Estado do Rio de Janeiro de 1979 a 1987 e 1989 [mimeografado]. Em: II Congresso Brasileiro de Epidemiologia, 13 a 17 de julho, Belo Horizonte, 1992.

26. Mello Jorge MHP, Latorre MRDO. Acidentes de trânsito no Brasil: dados e tendências. Cad Saude Publica 1994;10(supl 1):19-44.

27. Souza ER, Assis SG. Mortalidade por violência em crianças e adolescentes do Município do Rio de Janeiro. J Bras Psiquiatr 1996;45(2): 85-94.

Manuscrito recebido em 5 de junho de 1995. Versão revisada aceita para publicação em 31 de maio de 1996.
ABSTRACT

Violence in Rio de Janeiro Municipality: risk areas and mortality trends among adolescents 10 to 19 years old
This study presents data on general mortality and mortality from external causes (traffic accidents and homicides) among adolescents 10 to 19 years of age in Rio de Janeiro Municipality, Brazil, from 1980 to 1994. The purpose of the study was to describe and put into context mortality from external causes and to identify areas of the Municipality where the risk of these occurrences is highest. The study also sought to identify trends and seasonal patterns of this mortality and to place violence within the ambit of public health through application of the epidemiologic surveillance approach. Information on mortality was extracted from death certificates provided by the State Health Secretariat of Rio de Janeiro.

A total of 20224 death certificates were studied. The populations used as the denominators for determining rates were estimated from the censuses of 1980 and 1991. For purposes of the analysis, the Municipality was divided into eight programmatic areas, each composed of diverse neighboring districts. A time series analysis was done for traffic accidents and homicides. The results showed that external causes were the leading causes of death in the 10-19 age group, and that during the study period deaths from these causes had increased, especially among males. The results also revealed that mortality was heterogeneously distributed in areas of the Municipality that differed socioeconomically. The study points to the need for better integration of the health sector with other sectors and institutions and for a restructuring of the health system with regard to epidemiologic surveillance of violence. 